\title{
FLOATING MULTIPLE UNIT MINITABLETS OF METOPROLOL SUCCINATE: FORMULATION, IN VITRO AND IN VIVO CHARACTERIZATION
}

\author{
MADHULITA PANDA ${ }^{1 *}$, M. E. BHANOJI RA0 ${ }^{1}$, JNYANARANJAN PANDA ${ }^{1}$, C. H. NIRANJAN PATRA1, GANESH PATRO² \\ 1Roland Institute of Pharmceutical Sciences, Berhampur 760010, Ganjam, Odisha, ²ollege of Pharmaceutical Sciences, Mohuda, Ganjam, \\ Odisha, India \\ *Email: madhupanda026@gmail.com \\ Received: 10 Feb 2021, Revised and Accepted: 15 Mar 2021
}

\section{ABSTRACT}

Objective: In this present research, formulation of floating multiple unit minitablets of metoprolol succinate without using gas generating agent was attempted with an objective of increased residence time, sustained release, and improved oral bioavailability.

Methods: Solid dispersions were prepared with lipophilic carriers such as compritol AT0888, Gelucire 43/01, Gelucire 39/01, and precirol AT0 05 was formulated using fusion technique. Neusillin US2 was used as an adsorbent. The solid dispersions were compressed into minitablets, weighing $20 \mathrm{mg}$, and then filled into '0' size capsule.

Results: Formulation F9, F10, F14, and F15 showed instantaneous floating lag time, i.e., 0 min, floating time more than 12 h, and sustained release up to $12 \mathrm{~h}$. Pharmacokinetic study of the optimized formulation (F9) showed 2.46 times increase in area under the curve with increased residence time.

Conclusion: Hence gelucire 43/01 based floating multiple unit minitablets of metoprolol succinate can be considered a promising approach.

Keywords: Gelucire 43/01, Bioavailability, Stability, Floating lag time

(C) 2021 The Authors. Published by Innovare Academic Sciences Pvt Ltd. This is an open access article under the CC BY license (https://creativecommons.org/licenses/by/4.0/)

DOI: https://dx.doi.org/10.22159/ijap.2021v13i3.41066. Journal homepage: https://innovareacademics.in/journals/index.php/ijap

\section{INTRODUCTION}

For a long time, oral controlled release (CR) formulations are popularly used for controlling the release of drugs. Short transit time of drug with absorption window in the stomach causes drug release in the non-absorbing distal segment of GIT, leading to poor bioavailability [1]. These features are responsible for the design of gastro retentive formulations [2, 3]. Dose-dumping is the main disadvantage of sustained-release single-unit dosage form due to the failure of formulations [4, 5]. Like other multiple unit systems, minitablets can be considered a promising approach that releases the drug from the subunits (minitablets) after the capsule's disintegration $[6,7]$.

The drug having a short biological half-life favors the development of a sustained release. In contrast, the drug with an absorption window in the upper GI tract favors developing a floating drug delivery system, respectively $[8,9]$. Metoprolol Succinate, a $\beta$ selective adrenergic blocking agent, is used to treat patients with hypertension or angina pectoris [10]. Metoprolol succinate has a short half-life (3-4 h), and absorption window in the upper GI tract favors developing a sustained release and floating drug delivery system, respectively $[11,12]$. It exhibits a high solubility at gastric $\mathrm{pH}$ 1.2. Hydrophobic polymer can be used in the preparation of sustained and floating formulations. Hydrophobicity of certain carriers such as Compritol ATO 888, Gelucire 43/0, Gelucire 39/01, and precirol ATO 05 is why their release retarding ability [13]. Their low melting point makes them suitable for the melt granulation method. Higher concentrations of lipophilic carriers promote better control of the drug release because of increased lipid matrix density and long diffusion path length $[14,15]$. Hence in the present research work, it is planned to use hydrophobic carriers to formulate floating multiple unit minitablets of metoprolol succinate to achieve floating with sustain release for $12 \mathrm{~h}$.

\section{MATERIALS AND METHODS}

Metoprolol succinate was received as a gift sample from Mepro Pharmaceutical Ltd (Gujrat, India). Neusilin US2 was kindly provided as ex-gratis by Gangwal Chemicals Pvt Ltd (Mumbai, India). Compritol ATO 888, Gelucire 43/01, Gelucire 39/01, and precirol ATO 05 were provided as a gift sample from Gattefosse Pvt Ltd
(Mumbai, India). All other chemicals and solvents used were of analytical grade.

\section{Preparation of floating minitablets of metoprolol succinate}

Fusion method was adopted for preparing the solid dispersion of metoprolol succinate with a lipophilic carrier such as compritol ATO 888, gelucire 43/01, gelucire 39/01, and precirol ATO 05. The lipophilic carrier was melted on a water bath with continuous stirring. To the molten lipid dispersion, metoprolol succinate was added and mixed for $10 \mathrm{~min}$. The Neusillin US2 was added to the dispersion with continued mixing for 10 min to solidify the molten mass. Then the solid dispersion was sieved through mesh no. \# 40 . The resultant dispersion granules were compressed into $3 \mathrm{~mm}$ circular flat minitablets and were filled into a gelatine capsule of size '0' [16].

\section{Fourier transform infrared spectroscopy (FT-IR)}

FT-IR analysis of pure drug metoprolol succinate and its dispersion granules in 1:1 ratio with compritol AT0888, gelucire 43/01, gelucire 39/01, precirol ATO 05, and neusillin US2 were studied on IR Affinity-1 (Shimadzu, Japan) using potassium bromide discs. Samples were analyzed at a scanning speed of $2 \mathrm{~mm} / \mathrm{s}$ with a resolution of $4 \mathrm{~cm}-1$ over the region $4000-400 \mathrm{~cm}-1$.

\section{Differential scanning calorimeter (DSC)}

The pure drug metoprolol succinate and its dispersion granules with carriers were examined for compatibility study employing DSC (Shimazu Ltd., Japan). All the accurately weighed samples were placed in sealed aluminum pans before placing the pan on the sample holder at a scanning rate of $100 \mathrm{C} / \mathrm{min}$ from room temperature up to $2200 \mathrm{C}$. An empty aluminum pan was used as a reference. The DSC curve was plotted over a temperature range to predict the thermodynamic compatibility [17].

\section{Drug content}

Drug content of dispersion granules and mini tablets were determined by weighing an amount equivalent to $10 \mathrm{mg}$ of metoprolol succinate in $0.1 \mathrm{~N} \mathrm{HCl}$, sonicated for $5 \mathrm{~min}$, filtered, and analyzed UV spectrophotometrically at $273 \mathrm{~nm}$. 


\section{Micromeritic properties of dispersion granules}

The pure drug metoprolol succinate and dispersion granules of all the prepared formulations were characterized for various micromeritic properties. The bulk density, tap density, angle of repose, Carr's Index, and Hausner's ratio of all the formulations were determined as per standard procedure [18].

\section{In vitro buoyancy studies}

\section{Measurement of floating lag time}

The floating lag time was determined by conducting In vitro buoyancy studies for each of the formulation. The required number of floating minitablets was placed in a dissolution jar containing $900 \mathrm{ml}$ of $0.1 \mathrm{~N} \mathrm{HCl}$. Floating lag time may be defined as the time required for each of the minitablet to start floating on the surface of the dissolution media [19].

\section{Measurement of floating time}

Floating minitablets were placed in USP dissolution apparatus-II containing $900 \mathrm{ml}$ of $0.1 \mathrm{~N} \mathrm{HCl}$ to determine each formulation's floating time. Floating time is the total duration of floating when a dosage form is placed in a dissolution media [20].

\section{Evaluation of post-compression parameters}

The compressed minitablets were subjected to various quality control tests such as weight variation, hardness, thickness, friability, and drug content as per the standard procedure [21-23].

\section{In vitro dissolution studies}

The In vitro dissolution studies of different floating minitablets were conducted in a USP dissolution apparatus-II taking $0.1 \mathrm{~N} \mathrm{HCl}$ as dissolution medium. $5 \mathrm{ml}$ sample was withdrawn at regular time intervals up to $12 \mathrm{~h}(0.5,1,1.5,2,4,6,8,10$, and $12 \mathrm{~h})$ and was analyzed using UV-spectrophotometer at $273 \mathrm{~nm}$. The drug release study's kinetics were analyzed from the dissolution data by using zero-order, first-order, Higuchi, and Korsmeyer-Peppas model $[24,25]$.

\section{Accelerated stability study}

Accelerated stability study of the prepared floating minitablets (F9 and F14) of metoprolol succinate was conducted for a period of 3 mo as prescribed in ICH guidelines. The formulations were examined at the time points of $0,1,2$, and 3 mo for the different parameters.

\section{In vivo pharmacokinetic study}

The dose of metoprolol succinate was calculated as $9.2 \mathrm{mg}$ for each rabbit of weight approximately $2 \mathrm{~kg}$. The optimized formulation and aqueous dispersion of metoprolol succinate were administered in dispersion to six male rabbits, each in two groups using Ryle's tube [26]. At different time points $(0.5,2,4,8,12$, and $24 \mathrm{~h})$, a blood sample of $0.5 \mathrm{ml}$ was withdrawn from the rabbit's marginal ear vein. Each blood sample was centrifuged for $10 \mathrm{~min}$ at $3000 \mathrm{rpm}$, and the supernatant layer, i.e., serum, was collected using a micropipette. All the samples were analyzed using the reverse-phase ultrafast liquid chromatographic (UFLC) method. The various pharmacokinetic parameters like elimination rate constant $(\mathrm{K})$, half-life $\left(\mathrm{t}_{1 / 2}\right)$, peak plasma concentration (Cmax), time to attain the peak plasma concentration (Tmax), area under the curve (AUC), area under the first moment curve (AUMC) and mean residence time (MRT) were calculated. The animal experiment was approved by Institutional Animals Ethics Committee [926/PO/Re/5/06/CPCSEA, Approval No.97].

\section{RESULTS AND DISCUSSION}

The composition of solid dispersion with different ratios $(1: 1,1: 2$, $1: 3,1: 4$, and 1:5) of drug with the lipophilic carrier such as compritol ATO 888, gelucire 43/01, gelucire 39/01, and precirol ATO 05 are given in (table 1). The ratio of lipophilic carrier to adsorbent Neusillin US2 to is maintained at 1:0.5. Each minitablet weighing 20 $\mathrm{mg}$ is filled into a ' 0 ' size capsule. The composition of each formulation of floating minitablets is illustrated in table 4 .

Table 1: Composition of solid dispersion

\begin{tabular}{|c|c|c|c|c|c|c|}
\hline Formulations & $\begin{array}{l}\text { Metoprolol } \\
\text { succinate }\end{array}$ & $\begin{array}{l}\text { Compritol } \\
\text { AT0 } 88\end{array}$ & $\begin{array}{l}\text { Gelucire } \\
43 / 01\end{array}$ & $\begin{array}{l}\text { Gelucire } \\
39 / 01 \\
\end{array}$ & $\begin{array}{l}\text { Precirol } \\
\text { AT0 } 5 \\
\end{array}$ & Neusillin US2 \\
\hline F1 & 1 & 1 & - & - & - & 0.5 \\
\hline $\mathrm{F} 2$ & 1 & 2 & - & - & - & 1 \\
\hline F3 & 1 & 3 & - & - & - & 1.5 \\
\hline F4 & 1 & 4 & - & - & - & 2 \\
\hline F5 & 1 & 5 & - & - & - & 2.5 \\
\hline F6 & 1 & - & 1 & - & - & 0.5 \\
\hline F7 & 1 & - & 2 & - & - & 1 \\
\hline F8 & 1 & - & 3 & - & - & 1.5 \\
\hline F9 & 1 & - & 4 & - & - & 2 \\
\hline F10 & 1 & - & 5 & - & - & 2.5 \\
\hline F11 & 1 & - & - & 1 & - & 0.5 \\
\hline F12 & 1 & - & - & 2 & - & 1 \\
\hline F13 & 1 & - & - & 3 & - & 1.5 \\
\hline F14 & 1 & - & - & 4 & - & 2 \\
\hline F15 & 1 & - & - & 5 & - & 2.5 \\
\hline F16 & 1 & - & - & - & 1 & 0.5 \\
\hline F17 & 1 & - & - & - & 2 & 1 \\
\hline F18 & 1 & - & - & - & 3 & 1.5 \\
\hline F19 & 1 & - & - & - & 4 & 2 \\
\hline F20 & 1 & - & - & - & 5 & 2.5 \\
\hline
\end{tabular}

Drug-polymer interactions are an important parameter in selecting appropriate polymers. FT-IR spectroscopy study was employed to ascertain the compatibility between Metoprolol succinate and selected polymers. FT-IR study for the pure drug metoprolol succinate showed absorption bands at $3181 \mathrm{~cm}-1$ assigned to the NH group, absorption bands at $3040 \mathrm{~cm}-1$ assigned to $\mathrm{OH}$ group, and absorption bands at
$2740 \mathrm{~cm}-1$ assigned to $\mathrm{OCH}_{3}$ group. The dispersion granules of metoprolol succinate with different excipients such as compritol ATO 888, gelucire 43/01, gelucire 39/01, precirol ATO 05 and neusillin US2 also showed absorption bands in a similar range; hence metoprolol succinate and carriers were compatible with each other [27]. The overlaying FT-IR spectrum was shown in fig. 1. 


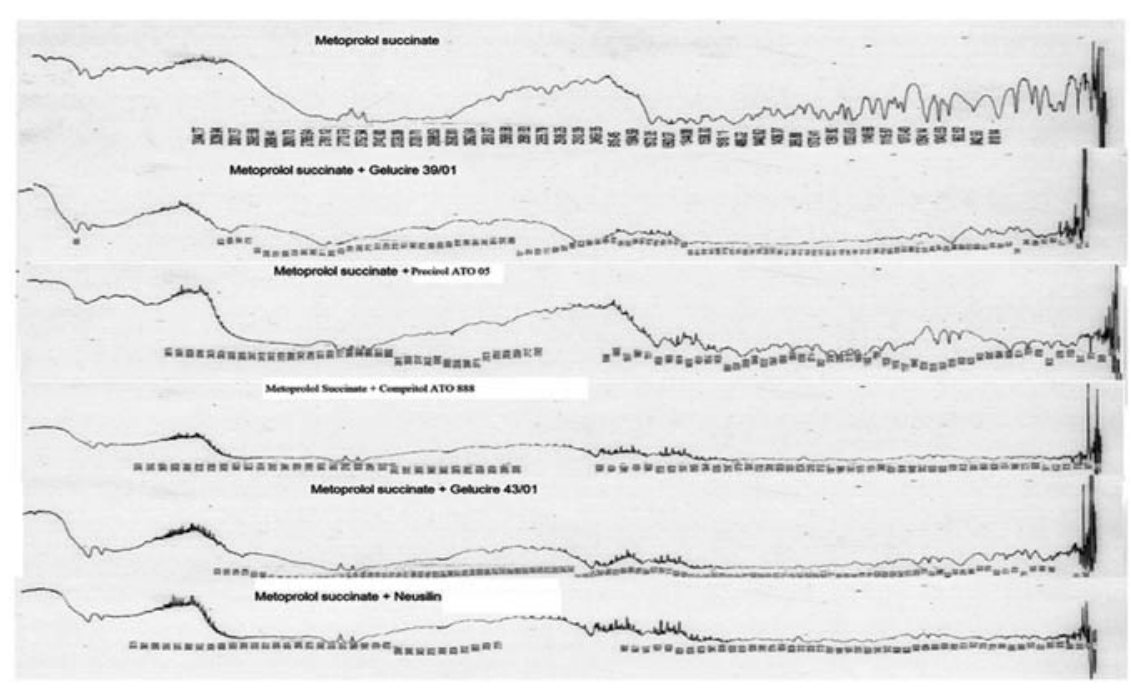

Fig. 1: FT-IR study for metoprolol succinate and its dispersion granules

DSC study revealed that the pure drug metoprolol succinate showed a sharp endothermic peak at $137.60 \mathrm{C}$ with a narrow melting range of onset temperature of $1340 \mathrm{C}$ and end set temperature $1420 \mathrm{C}$. The peaks remained nearly the same in all formulations (fig. 2A and 2B).
This confirms that no significant overlapping or shifting of the peak in the thermogram. However additional peak for each carrier was observed [17]. These results of DSC ratifies that the carriers used in the present study are compatible with metoprolol succinate.
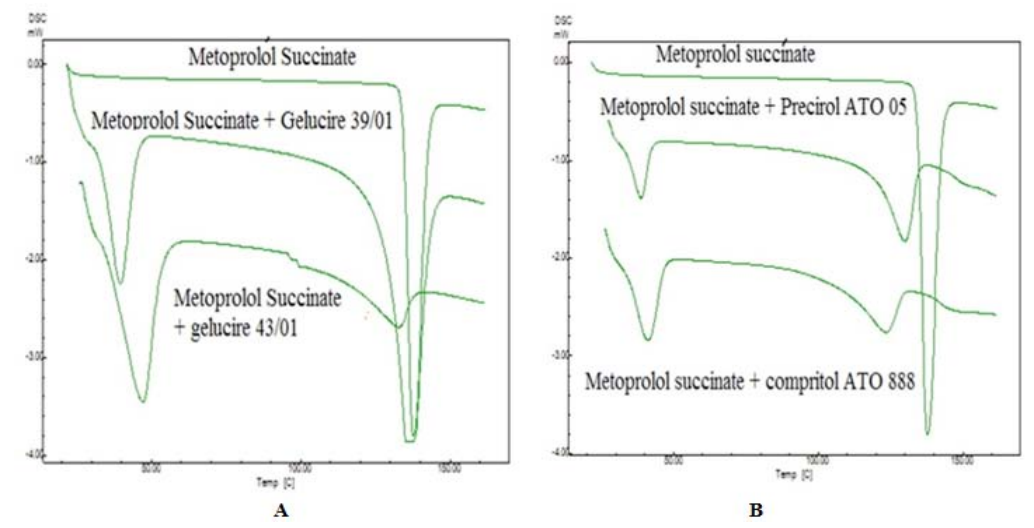

Fig. 2: DSC study for metoprolol succinate and its dispersion granules

Table 2: Micromeritic properties of solid dispersions

\begin{tabular}{lllll}
\hline Formulations & ${ }^{*}$ Angle of repose $\left(^{\circ}\right.$ ) & ${ }^{*}$ Carr's index (C. I.) & ${ }^{*}$ Hausner's ratio (H. R.) & ${ }^{*}$ Drug content (\%) \\
\hline Metoprolol succinate & $38 \pm 1.2$ & $30 \pm 2.3$ & $1.52 \pm 1.7$ & $96.7 \pm 3.1$ \\
F1 & $34 \pm 1.5$ & $28 \pm 2.2$ & $1.32 \pm 0.2$ & $99 \pm 3.9$ \\
F2 & $32 \pm 2.1$ & $27 \pm 1.5$ & $1.27 \pm 0.1$ & $96.5 \pm 1.2$ \\
F3 & $35 \pm 2.2$ & $28 \pm 2.1$ & $1.28 \pm 0.2$ & $96 \pm 2.3$ \\
F4 & $33 \pm 1.4$ & $26 \pm 1.4$ & $1.28 \pm 0.2$ & $99 \pm 3.2$ \\
F5 & $29 \pm 2.1$ & $1.29 \pm 0.3$ & $98 \pm 1.4$ \\
F6 & $27 \pm 2.2$ & $26 \pm 2.5$ & $1.30 \pm 0.3$ & $96 \pm 2.6$ \\
F7 & $31 \pm 1.6$ & $25 \pm 2.1$ & $1.31 \pm 0.2$ & $97 \pm 3.1$ \\
F8 & $32 \pm 3.2$ & $26 \pm 2.4$ & $1.28 \pm 0.3$ & $98 \pm 4.7$ \\
F9 & $33 \pm 2.5$ & $18 \pm 1.3$ & $1.30 \pm 0.3$ & $98 \pm 2.3$ \\
F10 & $19 \pm 2.1$ & $1.14 \pm 0.2$ & $97 \pm 3.3$ \\
F11 & $18 \pm 1.3$ & $1.31 \pm 0.4$ & $95 \pm 2.6$ \\
F12 & $18 \pm 2.4$ & $1.19 \pm 0.4$ & $97 \pm 3.7$ \\
F13 & $17 \pm 3.6$ & $1.17 \pm 0.3$ & $96 \pm 5.4$ \\
F14 & $24 \pm 2.5$ & $19 \pm 1.2$ & $1.21 \pm 0.2$ & $98 \pm 6.2$ \\
F15 & $25 \pm 1.5$ & $1.25 \pm 0.2$ & $97 \pm 5.1$ \\
F16 & $22 \pm 2.4$ & $1.22 \pm 0.7$ & $96 \pm 3.2$ \\
F17 & $24 \pm 1.5$ & $18 \pm 2.2$ & $1.18 \pm 0.4$ & $96 \pm 4.1$ \\
F18 & $23 \pm 2.1$ & $17 \pm 1.3$ & $1.21 \pm 0.3$ & $98 \pm 5.2$ \\
F19 & $24 \pm 2.2$ & $16 \pm 2.5$ & $1.22 \pm 0.2$ & $97 \pm 5.2$ \\
F20 & $22 \pm 3.0$ & $20 \pm 1.3$ & $1.21 \pm 0.3$ & \\
\hline
\end{tabular}

\footnotetext{
$*$ mean $\pm S D, n=6$
} 
The drug content for all dispersion granules was more than $90 \%$ indicating uniform mixing of drug with carriers (table 2). As the drug is dissolved in the molten mass of lipid, it exhibited better drug content than other granulation methods. The micromeritic parameters for all the formulation as well as the pure drug were studied, and the results are depicted in table 2. The pure drug's micrometric properties revealed that the flowability and compressibility were very poor for processing into the tablet dosage form. All the dispersion granules showed that the value of angle of repose, C. I and H. R were within the specified limit. This may be due to the engulfment of the drug in the molecular structure of the lipid matrix. Due to high oil adsorption capacity, the high specific surface area of neusillin US2 helps improve compressibility and flowability of the prepared dispersion, which can be predicted from their micrometric properties. Similar results were also reported about the oil adsorption capacity of neusillin US2 for gelucire based dispersion granules [16].
The In vitro buoyancy study was done, and the value of density, floating lag time, and floating time for all the prepared formulations are illustrated in table 3 . As all floating minitablets' density was much lower than the GI fluid density, it was expected that all minitablets would float. However, peculiar results were observed in floating behavior. Minitablets formulated with gelucire 43/01, and gelucire $39 / 01$ showed an instantaneous floating behavior, i.e., floating lag time of $0 \mathrm{~min}$ and floating duration of more than $12 \mathrm{~h}$. In contrast, floating minitablets formulated with compritol ATO 888 and precirol ATO 05 did not exhibit floating despite the low density of minitablets. However, Patel, 2015 reported good floating behavior for compritol based granules for ranitidine [15]. The In vitro buoyancy study reveals that hydrophobic lipid coat around drug particles' surface is the prime reason for floating behavior. It is also predicted that hydrophobicity and density alone may not be responsible for achieving desirable floating. The nature of the lipid matrix also played a significant role in achieving desired floating characteristics.

Table 3: Determination of density, floating characteristic of mini tablets

\begin{tabular}{|c|c|c|c|c|}
\hline Formulations & ${ }^{*}$ Density (g. $\mathrm{cm}^{-3}$ ) & Floating lag time (min) & Floating duration (h) & \% Floating \\
\hline F1 & $0.24 \pm 0.01$ & No floating & No floating & No floating \\
\hline $\mathrm{F} 2$ & $0.23 \pm 0.03$ & “ & “ & “ \\
\hline F3 & $0.27 \pm 0.03$ & “ & “ & “ \\
\hline $\mathrm{F} 4$ & $0.26 \pm 0.02$ & “ & “ & “ \\
\hline F5 & $0.23 \pm 0.04$ & “ & “ & $“$ \\
\hline F6 & $0.19 \pm 0.03$ & 0 & $>24$ & 100 \\
\hline F7 & $0.22 \pm 0.02$ & 0 & $>24$ & 100 \\
\hline F8 & $0.22 \pm 0.03$ & 0 & $>24$ & 100 \\
\hline F9 & $0.25 \pm 0.04$ & 0 & $>24$ & 100 \\
\hline F10 & $0.20 \pm 0.02$ & 0 & $>24$ & 100 \\
\hline F11 & $0.21 \pm 0.01$ & 0 & $>24$ & 100 \\
\hline F12 & $0.23 \pm 0.03$ & 0 & $>24$ & 100 \\
\hline F13 & $0.22 \pm 0.02$ & 0 & $>24$ & 100 \\
\hline F14 & $0.21 \pm 0.03$ & 0 & $>24$ & 100 \\
\hline F15 & $0.24 \pm 0.02$ & 0 & $>24$ & 100 \\
\hline F16 & $0.27 \pm 0.03$ & No floating & No floating & No floating \\
\hline F17 & $0.23 \pm 0.03$ & " & $"$ & " \\
\hline F18 & $0.24 \pm 0.02$ & $“$ & $“$ & $“$ \\
\hline F19 & $0.22 \pm 0.01$ & $“$ & $“$ & $"$ \\
\hline F20 & $0.21 \pm 0.02$ & “ & $“$ & “ \\
\hline
\end{tabular}

${ }^{*}$ mean \pm SD, $\mathrm{n}=6$

The result of the different formulations' quality control test showed that the various parameters such as drug content, hardness, friability, and disintegration test were within the acceptable specification. The In vitro dissolution study of the formulations was carried out, and the plot of cumulative percentage drug release against time is illustrated in fig: $3 \mathrm{~A}$ and $3 \mathrm{~B}$. The resultant plot suggests that the formulation F9, F10, F14, and F15 were found to achieve the desirability of sustaining the drug release for $12 \mathrm{~h}$. Similar sustain release of drug was also reported for gelucire 43/01 based floating beads [14].

Table 4: Composition of floating mini tablets

\begin{tabular}{|c|c|c|c|c|c|}
\hline \multirow[t]{2}{*}{ Ingredients } & \multicolumn{4}{|c|}{ Quantity drug and carriers (mg) in each solid dispersion formulation } & \multirow{2}{*}{$\begin{array}{l}\text { Number of minitablets } \\
\text { for } 100 \mathrm{mg} \text { dose }\end{array}$} \\
\hline & Metprolol succinate & Gelucire 43/01 & Gelucire 39/01 & Neusillin US2 & \\
\hline F6 & 8 & 8 & - & 4 & 13 \\
\hline F7 & 5 & 10 & - & 5 & 20 \\
\hline F8 & 3.65 & 11 & - & 5.5 & 33 \\
\hline F9 & 2.8 & 11.5 & - & 5.7 & 35 \\
\hline F10 & 2.3 & 11.8 & - & 5.9 & 44 \\
\hline F11 & 8 & - & 8 & 4 & 13 \\
\hline F12 & 5 & - & 10 & 5 & 20 \\
\hline F13 & 3.6 & - & 11 & 5.5 & 33 \\
\hline F14 & 2.8 & - & 11.5 & 5.7 & 35 \\
\hline F15 & 2.3 & - & 11.8 & 5.9 & 44 \\
\hline
\end{tabular}

Table 5 depicts the results of different drug release kinetic coefficients for formulations. All formulations exhibited a higher correlation for Higuchi equation, and formulations F9, F10, F14, and F15 showed release exponent greater than 0.5 less than 1 . F9 and F14 were found to achieve the desirability of sustaining the drug release for $12 \mathrm{~h}$. Hence lipid carrier gelucire 43/01 and gelucire 39/01are effectively control the drug release in a particular composition. Based on the dissolution study F9 and F14 can be predicted to satisfy all the floating multiple unit minitablet. Formulation F10 and F15 also showed sustained release for 12 h; however, keeping in view the minimum amount of carrier, formulation F9 and F14 were selected. 
Table 5: In vitro drug release kinetics

\begin{tabular}{|c|c|c|c|c|}
\hline \multirow[t]{2}{*}{ Formulations } & \multicolumn{3}{|c|}{ Correlation coefficients $\left(r^{2}\right)$} & \multirow[t]{2}{*}{ Korsmeyer release exponent (n) } \\
\hline & Zero-order & First-order & Higuchi model & \\
\hline F6 & 0.7593 & 0.9606 & 0.8190 & 0.2028 \\
\hline F7 & 0.8121 & 0.9732 & 0.9660 & 0.4211 \\
\hline F8 & 0.7237 & 0.9790 & 0.9986 & 0.5056 \\
\hline F9 & 0.9736 & 0.9902 & 0.9998 & 0.5299 \\
\hline F10 & 0.9665 & 0.9998 & 0.9914 & 0.5141 \\
\hline F11 & 0.6717 & 0.9873 & 0.9472 & 0.2157 \\
\hline F12 & 0.7928 & 0.9801 & 0.8375 & 0.2528 \\
\hline F13 & 0.8505 & 0.9948 & 0.8838 & 0.5284 \\
\hline F14 & 0.9418 & 0.9949 & 0.9927 & 0.5305 \\
\hline F15 & 0.9381 & 0.9956 & 0.9959 & 0.5249 \\
\hline
\end{tabular}

Formulation F9 and F14 were examined for 3 mo of stability study as prescribed in the method section. The parameters such as drug content, floating lag time, floating time, time taken for more than 95 percent drug release (T95\%) of F9 and F14 at various intervals are illustrated in table 6 . Analysis of variance $(p<0.05$ levels $)$ indicated no significant change of the parameters during the stability study period for F9. However, formulation F14 showed a significant change in T95\%, which may be attributed to softening of gelucire $39 / 01$ at the stability study temperature of $400 \mathrm{C}$ due to its low melting point. Hence floating minitablet formulation F9 was selected for further pharmacokinetic study.

Table 6: Accelerated stability study for formulation F9 and F14

\begin{tabular}{|c|c|c|c|c|c|c|c|c|}
\hline \multirow[t]{2}{*}{ Time in months } & \multicolumn{4}{|c|}{ Characterization of F9 formulation } & \multicolumn{4}{|c|}{ Characterization of F14 formulation } \\
\hline & $\begin{array}{l}{ }^{*} \text { Drug } \\
\text { content }(\%)\end{array}$ & $\begin{array}{l}\text { *Floating lag } \\
\text { time (sec) }\end{array}$ & $\begin{array}{l}\text { *Floating } \\
\text { duration (h) }\end{array}$ & $\begin{array}{l}* \mathrm{~T} 95 \\
\% \\
\end{array}$ & $\begin{array}{l}{ }^{*} \text { Drug } \\
\text { content }(\%)\end{array}$ & $\begin{array}{l}\text { *Floating lag } \\
\text { time (h) }\end{array}$ & $\begin{array}{l}\text { *Floating } \\
\text { duration (h) }\end{array}$ & $\begin{array}{l}* \mathrm{~T} 95 \% \\
\text { (h) }\end{array}$ \\
\hline 0 & $99 \pm 2.3$ & 0 & $>12$ & $12 \pm 0.2$ & $96 \pm 5.4$ & 0 & $>12$ & $12 \pm 0.5$ \\
\hline 1 & $98 \pm 3.2$ & 0 & $>12$ & $12 \pm 0.3$ & $97 \pm 3.2$ & 0 & $>12$ & $9 \pm 0.2$ \\
\hline 2 & $99 \pm 2.5$ & 0 & $>12$ & $12 \pm 0.5$ & $96.5 \pm 2.5$ & 0 & $>12$ & $9.5 \pm 0.4$ \\
\hline 3 & $98 \pm 4.1$ & 0 & $>12$ & $12 \pm 0.4$ & $96 \pm 4.1$ & 0 & $>12$ & $9.3 \pm 0.3$ \\
\hline $\begin{array}{l}\text { Significance } \\
\text { At } P<0.05 \text { level }\end{array}$ & No sig & No sig & No sig & No sig & No sig & No sig & No sig & $* *$ \\
\hline
\end{tabular}

${ }^{*}$ mean \pm SD, $n=6$, No sig $=$ No significant difference, ${ }^{* *}$ Significant

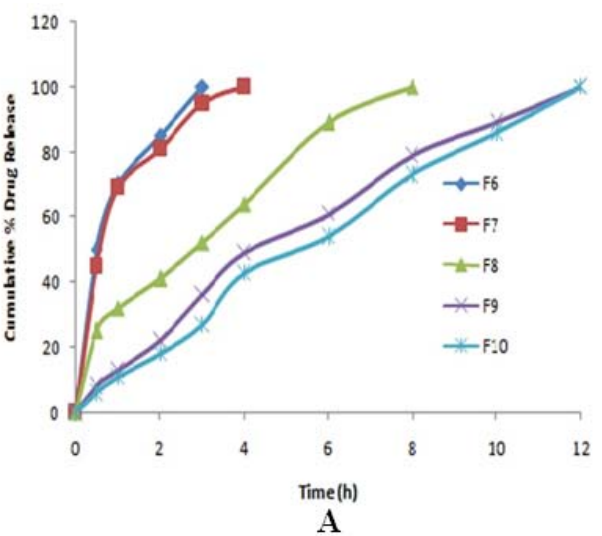

A

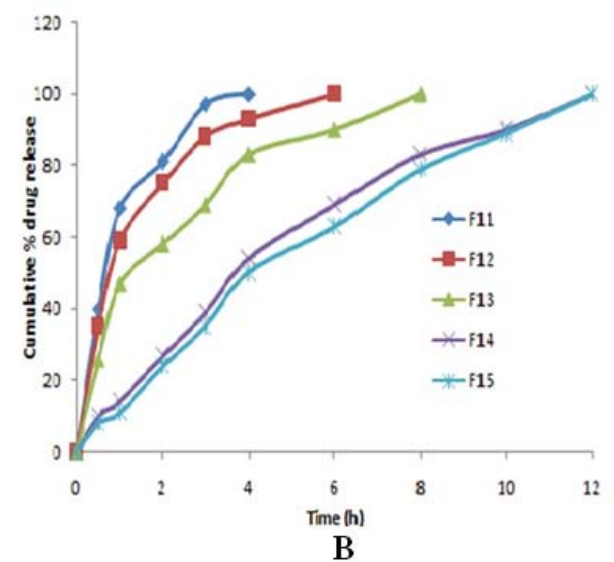

B

Fig. 3: In vitro drug release profile of gelucire 43/01(3A) and 39/01 (3B) based floating minitablets

Fig. 4 illustrates the mean serum drug concentration of metoprolol succinate vs. time graph of the optimized formulation F9 and an aqueous suspension of the pure drug after conducting the pharmacokinetic study. UFLC method for estimating metoprolol succinate using mobile phase acetonitrile: potassium dihydrogen phosphate (90:10), C18 column, flow rate $1 \mathrm{ml} / \mathrm{min}$ estimates retention time of $3.7 \mathrm{~min}$. Table 7 illustrates the calculated values of different pharmacokinetic parameters. The Tmax for the pure drug was found to be $2 \mathrm{~h}$, whereas Tmax in the case of floating minitablet formulation (F9) was $4 \mathrm{~h}$, indicating sustain release of the drug. The AUC value of F9 was $167438.19 \mathrm{ng}$. h/ml. In contrast, it was $67821.98 \mathrm{ng} . \mathrm{h} / \mathrm{ml}$ for pure drug, indicating that floating minitablet
(F9) showed better bioavailability, which is 2.46 times than that of the aqueous suspension of pure drug metoprolol succinate. AUMC value for F9 was 2.6 times more than the pure drug. Cmax for metoprolol succinate was found to be $32125.12 \mathrm{ng} / \mathrm{ml}$, whereas, for the selected formulation (F9), it was found to be $40475.58 \mathrm{ng} / \mathrm{ml}$. Nearly 1. 2 times increase in Cmax value for F9 indicated better absorption of the drug from the formulation. Higher mean residence time (MRT) for F9, i.e., $5.96 \mathrm{~h}$ in GI tract, indicates increased residence time of the dosage form leading to improved bioavailability. Hence it may be inferred that it is possible to prepare gastro-retentive minitablets using gelucire $43 / 01$ as lipid matrix without using a gas generating agent. 
Table 7: Pharmacokinetics parameters

\begin{tabular}{lll}
\hline Pharmacokinetic parameters & Metoprolol succinate & Minitablet (F9) \\
\hline${ }^{*} \mathrm{C}_{\max }(\mathrm{ng} / \mathrm{ml})$ & $32125.12 \pm 234$ & $40475.58 \pm 432$ \\
${ }^{*} \mathrm{~T}_{\max }(\mathrm{h})$ & $2 \pm 0.03$ & $4 \pm 0.03$ \\
${ }^{*}$ AUC $(\mathrm{ng} . \mathrm{h} / \mathrm{ml})$ & $67821.98 \pm 478$ & $167438.19 \pm 769$ \\
${ }^{*}$ AUMC $\left(\mathrm{ng} . \mathrm{h}^{2} / \mathrm{ml}\right)$ & $192337.67 \pm 652$ & $519309.97 \pm 983$ \\
${ }^{*}$ MRT (h) & $2.8 \pm 0.04$ & $5.96 \pm 0.02$ \\
\hline
\end{tabular}

${ }^{*}$ mean \pm SD, $\mathrm{n}=6$

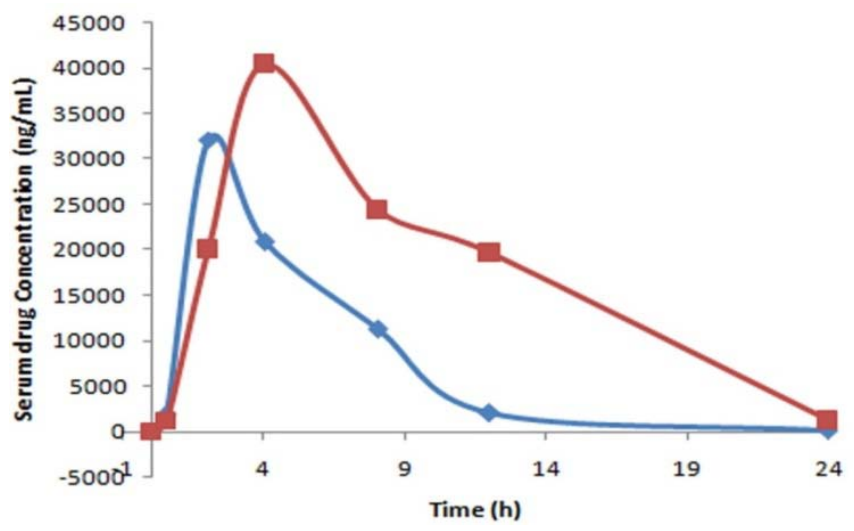

Fig. 4: Serum drug concentration-time profile of metoprolol succinate and floating minitablet formulation (F9)

\section{CONCLUSION}

In this present research work, formulation and development of floating minitablets of metoprolol succinate were carried out with desired sustainability and gastric residence time. Solid dispersion with different ratios $(1: 1,1: 2,1: 3,1: 4$, and 1:5) of drug with the lipophilic carrier such as compritol ATO 888, gelucire 43/01, gelucire 39/01, and precirol ATO 05 was formulated using fusion technique. The ratio of lipophilic carrier to adsorbent neusillin US2 is maintained at 1:0.5. Each minitablet weighing $20 \mathrm{mg}$ is filled into a ' 0 ' size capsule. Floating minitablets prepared with compritol ATO 888 and Precirol ATO 05 did not exhibit floating, whereas gelucire 43/01 and 39/01 floating minitablets without gas generating agent exhibited desirable floating and sustain release characteristics. Stability study as per ICH guideline suggests that gelucire 39/01 based floating minitablets were not stable, but gelucire $43 / 01$ based floating minitablets passed the stability test. The pharmacokinetics study of the selected formulation (F9) showed 2.46 times increase in AUC with increased residence time compared to an aqueous suspension of metoprolol succinate. From the above research work, it may be concluded that sustain release gastro-retentive minitablets can be prepared using gelucire $43 / 01$ without using gas generating agents. Hence, gelucire 43/01 based minitablets can be considered a promising approach for the formulation of sustain release with gastric retention.

\section{FUNDING}

Nil

\section{AUTHORS CONTRIBUTIONS}

All authors have contributed equally.

\section{CONFLICT OF INTERESTS}

All authors declare no conflict of interest.

\section{REFERENCES}

1. Hoffman A. Pharmacodynamic aspects of sustained-release preparations. Adv Drug Delivery Rev 1998;33:185-99.

2. Streubel A, Siepmann J, Bodmeier R. Gastroretentive drug delivery systems. Expert Opin Drug Delivery 2006;3:217-33.

3. Pawar VK, Kansal S, Garg G, Awasthi R, Singodia D, Kulkarni GT. Gastroretentive dosage forms: a review with special emphasis on floating drug delivery systems. Drug Delivery 2011;18:97110.

4. Abdul S, Chandewar AV, Jaiswal SB. A flexible technology for modified-release drugs: multiple-unit pellet system (MUPS). J Controlled Release 2010;147:2-16.

5. Kawashima Y, Niwa T, Takeuchi H, Hino T, Ito Y. Preparation of multiple unit hollow microspheres (microballoons) with acrylic resin containing tranilast and their drug release characteristics (in vitro) and floating behavior (in vivo). J Controlled Release 1991;16:279-89.

6. Lingam M, Ashok T, Venkateswaralu V, Rao MY. Design and evaluation of a novel matrix type multiple units as biphasic gastroretentive drug delivery systems. AAPS PharmSciTech 2008;9:1253-61.

7. Panda M, Rao MEB, Patra CN, Panda J, Panigrahi KC, Patro G. Formulation and development of floating multiple-unit minitablets of nimodipine without using a gas-generating agent: in vitro and in vivo characterization. Future J Pharm Sci 2020;6:1-9.

8. Singh BN, Kim KH. Floating drug delivery systems: an approach to oral controlled drug delivery via gastric retention. J Controlled Release 2000;63:235-59.

9. Lopes CM, Bettencourt C, Rossi A, Buttini F, Barata P. Overview on gastroretentive drug delivery systems for improving drug bioavailability. Int J Pharma 2016;510:144-58.

10. Sharma F, Jain H, Kanzariya V, Upadhyay U. Formulation and evaluation of controlled release osmotic tablet of metoprolol succinate. Asian J Pharm Clin Res 2014;7:38-43.

11. Rao GK, Mandapalli PK, Manthri R, Reddy VP. Development and in vivo evaluation of gastroretentive delivery systems for cefuroxime axetil. Saudi Pharm J 2013;21:53-9.

12. Kendall MJ, Maxwell SRJ, Sandberg A, Westergren G. Controlled release metoprolol. Clin Pharmacokinet 1991;21:319-30.

13. Panigrahi KC, Patra CN, Jena GK, Ghose D, Jena J, Panda SK. Gelucire: a versatile polymer for modified release drug delivery system. Future J Pharm Sci 2018;4:102-8.

14. Jain SK, Gupta A. Development of gelucire $43 / 01$ beads of metformin hydrochloride for floating delivery. AAPS PharmSciTech 2009;10:1128-36.

15. Patel DM, Patel NM, Patel VF, Bhatt DA. Floating granules of ranitidine hydrochloride-gelucire 43/01: formulation optimization using factorial design. AAPS PharmSciTech 2007;8:E25-31. 
16. Jammula S, Patra CN, Swain S, Panigrahi KC, Nayak S, Dinda SC. Design and characterization of cefuroxime axetil biphasic floating minitablets. Drug Delivery 2015;22:125-35.

17. Zheng X, Yang R, Tang X, Zheng L. Part I: characterization of solid dispersions of nimodipine prepared by hot-melt extrusion. Drug Dev Ind Pharm 2007;33:791-802.

18. Fonner DE, Banker GS, Swarbrick J. Micromeritics of granular pharmaceutical solids I: physical properties of particles prepared by five different granulation methods. J Pharm Sci 1966;55:181-6.

19. Arora S, Ali J, Ahuja A, Khar RK, Baboota S. Floating drug delivery systems: a review. AAPS PharmSciTech 2005;6:E372-90.

20. Shakya R, Thapa P, Saha RN. In vitro and in vivo evaluation of gastroretentive floating drug delivery system of ofloxacin Asian J Pharm Sci 2013;8:191-8.

21. Aulton ME, Taylor K. Aulton's pharmaceutics : the design and manufacture of medicines. Elsevier Health Science, London; 2013.

22. Fatema K, Shahi S. Development and evaluation of floating tablet of metoprolol succinate for increased bioavailability via in vivo study. Asian J Pharm Clin Res 2018;11:79-84.
23. Dighe PP, Tank HM. Design and statistical optimization of a bilayered tablet of metoprolol succinate sustained-release and atorvastatin calcium immediate release: once a day formulation in the management of hypertension. Asian J Pharm Clin Res 2018:11:293-302

24. Boldhane S, Kuchekar B. Development and optimization of metoprolol succinate gastroretentive drug delivery system. Acta Pharm 2010;60:415-25.

25. Thakkar VT, Shah PA, Soni TG, Parmar MY, Gohel MC, Gandhi TR. Goodness-of-fit model-dependent approach for release kinetics of levofloxacin hemihydrates floating tablet. Dissolution Technol 2009;16:35-9.

26. Panigrahi KC, Jena J, Jena GK, Patra CN, Rao MEB. QBD-based systematic development of bosentan SNEDDS: formulation, characterization and pharmacokinetic assessment. J Drug Delivery Sci Technol 2018;47:31-42.

27. Chandana CH Y, Kumar G, Vishnu YV, Madhuri MM. Metoprolol succinate sustained-release matrix tablets-formulation development and in vitro evaluation. Int J Pharm Pharm Sci 2014;6:481-6 